\title{
SOME FOUNDATIONAL AND METHODICAL PROBLEMS OF THE EMPIRICAL THEORY OF LITERATURE
}

\author{
W. KINDT *
}

This paper deals with some problems of the empirical study of literature. These problems are established on different levels and are related to the following questions: Which are objects for the empirical study of literature? Why does this study of literature require methods of logical analysis? How are categories oriented on participants and situations to be dealt with? Which theoretical foundations and methods for interpreting are provided by linguistics? What are normative tasks for the study of literature? In treating these questions, it is attempted, among other things, to point out differences and intersections between the empirical and the traditional study of literature.

\section{Introduction}

Although the purpose of this paper is to elucidate some problems in the empirical theory of literature, I would like to begin with a series of comments upon my estimation of the present situation in the study of literature. As a prerequisit to understanding this paper I would also like to expose my scientific and political interests. Since 1974 I have been cooperating with the NIKOL research group [1]. In this group, 1 , in a sense, play the part of an 'outsider': on the one hand, in contrast to other members of the group, I am not a skilled philologist; I was educated rather for mathematics and natural sciences; on the other hand, my research activities have only indirectly brought me in contact with problems of literary studies. Thus, to a certain extent I may be regarded as an 'amateur' within the group. Nevertheless, my

* I want to express my thanks to H. Hauptmeier for translating this paper into English.

Author's address: W. Kindt, Dresdener Strasse 2, D-4803 Steinhagen, W. Germany

[1] Cf. Schmidt (1980) for origins and intentions of the NIKOL group. I am very much obliged to S.J. Schmidt for the opportunity of my collaboration and its extraordinary circumstances. 1 dare say that criticism on the part of a logician, that is, criticism not only tolerated but even accepted as a constitutive element in discussions, is quite unique for research groups in the study of literature; and this is exactly the function of some critical arguments in this paper. It was one of my most impressive experiences in team-work having observed how much all members of the group profited from each other by interdisciplinary cooperation. In this way, many of my conceptions of the theories of language and literature were decisively supported by discussion in the NIKOL group. 
collaboration with that group is based on a serious interest in developing a theoretically well-founded, empirical theory of literature. Now, on the one hand, it is to be regretted that among many legitimate as well as scientifically substantial domains of activity, traditional studies in literature are still dominated by subjectivistic and logically unqualified modes of proceeding. Here it is also to be regretted that dogmas are stuck to, both hostile to empirical research and in agreement with an obsolete philosophy of science and language, hence nourishing political naivety and a certain remoteness to practice. On the other hand, the development of the empirical study of literature is just at its beginning and, accordingly, it has to overcome typical starting problems. It is this situation exactly, in which I deem it necessary to have an effect on the clarification of the logical structure of theories of literature, and to be at work on a sociological and linguistic foundation adequate for those theories. With regard to these two aims my activities in the group could not always be as intensive as to formulate problem-solving suggestions satisfying my own educationally affected demands. Besides the above-mentioned more general aims, I was mainly concerned with the enforcement of a more pragmatic view towards the following three subjects:

(1) Although it is necessary to determine metascientific norms which ale ideally capable of regulating our research, a far too rigid application of such norms may, however, obstruct innovating research. In my opinion, it is inadequate to interpret the postulate of empirical testability, for instance, in such a way that exclusively the so-called empirically 'hard' methods are declared admissible. For my part, we may permit a more flexible view here because the necessary degree of loyalty to norms depends on the desired degree of reliability of the statements concerned.

(2) An equilibrium between theoretical growth and empirical investigations has to be established. Whereas, on the one hand, empirical investigations which are not embedded in an appropriate theoretical frame may evoke a loss of orientation, theoretical growth, on the other hand, is in constant need of stimulating results from empirical investigations. This latter goal is frequently attained by empirically 'soft' methods alone.

(3) In my opinion the postulate of general 'value neutrality' is unacceptable. On principle, normative statements can be legitimated even in empirical sciences. On the one hand, certain social norms can partially be justified empirically; on the other hand, normative statements may be adopted for the construction of hypotheses without getting down to the problem of their degree of validity, as far as they are explicitly marked presuppositions.

Considering, among other things, the above-mentioned three arguments properly, it might henceforth be for the empirical theory of literature to elaborate a realistic and mythless evaluation of the function of literature within its numerous social contexts - and this would be a relevant social task for the study of literature. 
Within narrow bounds, traditional studies in literature have partially tried to formulate social frameworks for literary production and literary reception, to postulate desirable functions of literature, and to assign mediation tasks to themselves. In the urge of glorifying literature, however, traditional studies of literature have failed to provide critical analyses of the factual preconditions of the literature-system; they have even failed to reflect the realizability of the social functions of literature and to evaluate realistically their own practicability, i.e. their own chances for having influence on the literature-system. On the other hand, many empirically orientated approaches to the study of literature have to be blamed for insufficient or no reflection of the central question of the factual social function of literature and theory of literature. Moreover, there are in particular techniques of inquiry applied, inappropriate to many socio-political problems.

If scholars of literature want to represent more than useful figures for the legitimation of a social reality or practice intentionally deprived of a detailed scientific analysis, partly because of ideological motives, partly because of motives they are unaware of, then these scholars must, henceforth, not solely play the part of prophets of the higher values of literature and, at the same time, complain of a (pretended) lack of interest in literature. What annoys me particularly is that even those scholars of literature who call themselves critical scholars - since mainly the level of textual content is considered - help to maintain the immunization of mechanisms stabilizing authority and social classes (their analyses are frequently limited by deplorable statements as e.g., that workers can participate less in literary communicative interaction on account of their socialization and their economic situation). Furthermore, it is startling to observe how students of literature are educated without any orientation in view of the practical function of their studies and their future occupation, and, e.g., how unsuspecting students are about the normative functions of literary instruction at school. Even the usually postulated aim of education, i.e., qualification for competent participation in literary communicative interaction, has solely stabilizing effects upon the system, as long as this aim is handled uncritically; and at least it will remain a problem as long as the literaturesystem is not more accurately investigated empirically with regard to the factual functions of activities within the system.

Ever since 1976, when I argued for a close sociological analysis of the literaturesystem and the factual functions of literature in particular ( $c f$. Kindt and Schmidt 1979), the necessity for such an analysis has become increasingly clear to me. Thus, I suspect, for instance, that there is a considerable discrepancy between the real functions of literary reception and the functions proclaimed by professional representatives of the literature-system. Nevertheless, we cannot attach negative value to the fact that by receiving literature, literary text receivers will also look out for other interests than the ones officially proclaimed (e.g., the use of literary knowledge for indirect presentation of self; such a mode of action is absolutely legitimate, and besides, this will not always be fully apparent to the literary text receiver). Of a rather problematic nature are valuations pronounced upon reference to supposedly 
realized functions and, e.g., therewith providing chances for members of certain social strata to unjustified social prestige. In my opinion, it is likewise of grave consequence, if the stereotyped belief in the peculiarity of epistemic potentials of literature amounts to a disrepute of analytically orientated ways of thinking, and to systematical blockage of analytical methods in teaching.

These negative phenomena, the greater number of which I have become aware lately, gave me even more reasons for promoting the empirical theory of literature. Certainly, I am mainly interested in the sociological aspects on the one hand, and the linguistic-semantic aspects of literary interaction on the other. This remark will probably make the reader better understand my pleading for the use of interpretive methods. So it might be clear, for instance, that factual functions of literary reception cannot be investigated exclusively by direct methods of inquiry (e.g., questionnaires, polls). In that way, of course, we can at best measure 'aware' parts of these functions; possibly, questioned persons will solely reproduce - according to their socialization - internalized social clichés on the functions of literary reception, having little to do with real reception actions. Similar problems will arise from above-mentioned methods if text receivers are asked about their interpretation of a literary text ( $c f$. Kindt 1980b). Where traditional methods of inquiry may fail, interpretive methods - under certain conditions - mlay assist empirical research. Meanwhile, on the basis of positive experience in research in the semantic area, I am firmly convinced that interpretive methods as opposed to an extensively exercised hermeneutical practice in the study of literature, can be used as methodologically regulated and intersubjectively testable scientific operations; and that is, if interpretive methods are founded on a theory of interaction (for details, $c f$. Kindt 1980a). However, in contrast to other members of the NIKOL group, I am once more of the opinion that the central enterprise of literary scholars - though not exclusively - still consists of interpreting literary texts but surely in a new, nontraditional sense of the word.

Such an interpretation, however, will be meaningful only by a communicationand interaction-theoretical formulation of the questions concerned; and - according to present knowledge in linguistics - the degree of a detailed semantic analysis, as is required by traditional interpreting can by no means be reached. In particular cases, this kind of interpreting, i.e. in its function as an aid for the reconstruction of underlying author intentions, may meet with traditional interpreting insofar as its required function of mediation is concerned. The practice of extensively unfolding meaning potentials in traditional studies of literature (and the ideology of aesthetics derived from this practice) is yet incommensurable to an interactionalistic approach attempted to reduce the set of possible readings. Otherwise the interest of traditional scholars of literature for an empirical conception and its potentials for theoretical growth might rather be attained by treating problems of immediately transparent socio-political relevance; in addition, debates on these problems might help to break with the numerous traditional dogmas in the theories of science and literature. 


\section{Problems of ontology and object domain}

According to the conception of the study of literature propounded by the NIKOL group, efforts are being made for an empirical investigation of the entire socialaction-domain 'literature'. This domain consists of at least the following four subdomains: literary production, literary mediation, literary reception, literary postprocessing (for details, $c f$. Schmidt 1980). In some aspects the exposition provided by S.J. Schmidt is necessarily slightly global, and in my opinion, there are even some problematic details.

In the following section some still existing problems in the definition of the object domain will be discussed. Such problems, for instance, will be evident if decision procedures for the membership relation between observed actions and the literature-system have to be established not only concerning apparently trivial cases. The development of decision procedures presupposes a well-founded theoreticallybased ontology and an answer to the question of empirical accessibility to the objects; that is, first of all we have to discuss the problems of empirical identification of those types of objects, which are provided by the ontology.

At this point, it will be of some use to realize once more the problems of object domain in traditional conceptions, which are still exclusively text-oriented. In fact there are striking difficulties for the definition of literariness or a solution for methodological problems of interpreting, since in defining the object domain situational aspects and participant-views are neglected. Thus, an intensive and systematic discussion of these difficulties should have resulted necessarily in refined judgments on some foundational problems of the study of literature on the one hand and in an expansion of the object domain on the other. In my opinion, the lack of such a discussion can be attributed to the close alliance of conceptions of the study of literature with traditional schemes of thinking (oriented on intellectual history) about the nature of language. Those schemes even have influence on present research, and moreover, they are obstacles to critical epistemological reflection on language and communication. In the traditional study of literature, language and literature are declared ontologically autonomous (although this view contradicts the frequently emphasized individual and social determinacy of language). At the same time, it is attempted to explain linguistic/literary phenomena "out of themselves". Accordingly, the question of "what is literature?", for instance, is always answered out of language itself. Thus, an answer satisfactory to the point has never been found, and many traditional scholars might even be aware of this deficiency. However, this does not result in a problematization of the autonomy scheme and in a refined formulation of the question like, e.g., "what is literature to whom in which situation?". This question is, rather, evaded with reference to certain unfallible and untestable demarcational constructions (cf., e.g. Kayser 1960: 14; or Wellek and Warren 1978: 20-28), or even to mystifications (cf. Conrady's criticism in 1974: 97ff.). There is a similar situation for questions like,e.g., "what is the meaning of this text?". According to the autonomy-scheme, meaning is conceived as an autono- 
mous linguistic entity. The pressing experience in daily practice that results of reception depend on the preconditions of the receiver does not involve the surender of the assumption of autonomous textual meaning. Exactly, this assumption is maintained producing the non-empirical pseudo-problem of "how can we perceive the autonomous meaning of a text?". Consequently, this pseudo-problem and the experience mentioned above compels us to construct a - nowhere else existing - fundamental problem in epistemology: there could be no objective empirical access to autonomous textual meaning, but meaning could merely by discovered by the knowing subject, and, on principle, meaning would be overlapped by individual understanding.

This view on language as illustrated by the questions "what is literature?" and "what is the meaning of this text?" affects the treatment of questions in the study of literature, which are related to textual meaning and evaluation. For this reason, the dogmatic determination of the object domain has prevented empirical procedures and approaches to central problems in the study of literature; and it has also provided make-believe legitimations for the ideology of necessarily non-empirical conceptions. On the other hand, there could have been no constraints for modifications on the object domain since there were no attempts at finding empirical interpretations for problems in the study of literature. On the whole, the disadvantageous reciprocal relations between the definition of the object domain and nonempiricity is certainly one of the main reasons for a usually hostile position of the traditional study of literature to empirical conceptions.

An additional theoretical difficulty for the traditional study of literature is revealed by attempts to clarify the "mode of existence" of literary texts ( $c f, e . g$. Wellek and Warren 1978: Ch. 12). For an answer to this question, a look at common procedures of abstracting in modern linguistics (e.g. the introduction of phonemes and morphemes) would have helped to a certain extent. However, it must be said that linguistics according to the Saussurean conception have started out from a notion of sign, which cannot be very useful for an empirical theory of language because of its narrow tie between substance and form ( $c f$. Kindt 1981).

From the outset, the theoretical position advocated by Schmidt has been orientated on communicative actions. Thus, it could overcome aporetic problems of the traditional study of literature. In a similar way Schmidt rightly referred to the necessity of a pragmatic definition of literature. Nevertheless, the exact empirical and theoretical status of the central notions of Kommunikat and literariness is not clarified sufficiently in Schmidt (1980). It appears to me that - similar to traditional views - an inappropriate systematic discussion on problems in the development of ontology and on the empirical accessibility to research objects is responsible for this [2].

Concerning the notion of Kommunikat, despite its homogeneous, although logically somewhat incorrect definition, there are different uses of this notion in

[2] There have been numerous discussions on this aspect between S.J. Schmidt and me, with. out any final agreement. My own position has become more sharply defined since then. 
Schmidt 1980. In particular, the ontological status of Kommunikat is not accurately determined and furthermore, what actions communicative participants must perform in assigning a Kommunikat to a given text. On the one hand, the required result of the receiver's assigning act must be characterized more precisely, since Kommunikate in Schmidt 1980 are relevant research objects. On the other hand, such characterization would be opposed to the fact that from a functional point of view there are quite different levels of assigning acts in communication which, however, cannot be labelled one after another ( $c f$. Kindt 1980b). A more important argument is that in my opinion there is no necessity to introduce the notion of Kommunikat: I think it is impracticable to define such object constructions as primary research objects, which are accessible rather indirectly, and where it is not clear whether they correspond to participant concepts. If we take a more radical position on empirical methods, we will realize that e.g. in case of verbal communication a 'material' notion of text [3] is adequate (cf. Schmidt 1980: 73) and comparatively non-problematic in application.

If such communicative interactions are analyzed, where texts are used as communicative means, then the presupposition of a realization of the given text as a Kommunikat is already fulfilled relative to each interactionally specified level of assigning. Thus, the introduction of an additional autonomous concept, where the functions of texts are 'ontologized', is superfluous. If merely structural linguistic properties are analyzed, a textual view is anyhow adequate. I will not deal with the sophisticated problems of empirical interpretation of theoretical terms describing communicative interaction. Nevertheless, I would like to point out two problems connected with the use of a material notion of text. First, such a notion is no "pure material' notion; it implies a considerable amount of abstraction: in the domain of written language, for instance, we can abstract from the printed kind of type. Secondly, the contextual dependence of the notions of text and sign must be taken into account. This dependence is particularly important for literary interaction, and also for communication by means of written language (e.g. concrete poetry): one and the same printed figure, according to context, can be categorized each time as a different sign. In spoken language, the apperception of signs (i.e. the apperception of phonemes) is frequently contextually determined.

In Schmidt 1980, the realm of literary communicative interaction is marked by two scientific hypotheses: the aesthetic convention and the polyvalence convention. Originally, Schmidt did not conceive these conventions as hypotheses, but as conditions for defining aestheticity and literariness; on my suggestion, he later accepted the hypothesis-view. In my opinion, this view has three advantages: First, the form of hypotheses, that allows to predict participant relations from certain preconditions of text and situation, appears to be natural and fruitful. Secondly, it

[3] I have always argued for a 'material' notion of text in discussions with S.J. Schmidt, where he accepted my arguments on the practibility of a material notion of text, but he did not acknowledge the superfluity of the notion of Kommunikat. 
is reasonable if the conditions for the definition of aesthetic/literary interaction do not depend on a too complex state of affairs and are directly testable as far as possible. The latter purpose is much rather accomplished if it is asked whether participants realize texts as aesthetic/literary texts, as to prove that certain general meaning rules are applied or that other participants are always expected to follow these rules. Thirdly, if the hypothesis-view is once adopted, it is not necessary yet to determine whether to which degree, which social groups actually follow the two conventions. Thus, social stratifications and specifications of degree can be investigated subsequently. In my opinion, it is not at all plausible to suppose that above conventions are being followed without any exception; but only if this were the case would the conventions provide adequate defining conditions (I further claim that frequently those conventions are not being followed, that is, they are not conventions permanently valid for all groups of participants, but rather rules which are frequently valid or conventions in a weaker sense).

Naturally a decision in favor of the hypothesis-view does not exclude that in a concrete empirical investigation literary interaction may be inferred indirectly/ inductively from a confirmed observance of the conventions ( $c f$. also Kindt 1980a). Such a method, however, must not result in a confusion of definitional conditions and hypotheses.

Indeed, the exposition given in Schmidt 1980 is inconsequent insofar as in the definition of "literary", in contrast to the definition of "aesthetic", both conventions are used as definitional elements (1980: 139). Apart from this, it looks first of all as though Schmidt was right not to attach the predicates "aesthetic" or "literary" to texts but exclusively to Kommunikate (1980: 84). The attachment of these predicates might be restricted to respective communicative actions, but according to the usual manner of speaking it seems to be suitable to assign literariness/aesthet icity to underlying communicative objects, e.g. texts. Here the notion of Kommunikat would not yet be superfluous, in contrast to my above arguments.

A precise clarification of these problems will only be possible if the short comings of a rigid objectivistic ontology are realized beforehand. That texts according to the situation of a receiver are at one time received literary and non-literary at another and thus are processed differently, is an observation which is quite right in itself, but it is rather misleading to suppose that objects constructed over texts and not the text itself - would be categorized as literary objects. In general, objects could be categorized quite differently relative to situationally valid conditions (and particularly in accordance with respective interactional aims). Even seeming particulars of the object type "text" - that literariness is eventually realized by/during interpreting - do not require the introduction of the Kommunikat concept. The apperception of all types of objects may include interpretive procedures [4].

[4] An example appropriate to the time this paper was written is the following sentence: "This fir tree is beautiful". If one buys a.fir tree in the Chrismas shopping season, the trees in store at the merchant's will be realized according to their applicability as Christmas trees, and in the light of this realization the object will be rated. And in my opinion, this process (i.e. realization 
On the basis of this approach, an action is a literary action, if it is directed by a literary text.

In this context, we must furthermore ask how judgments on literariness are realized. In the theoretical approach of Kallmeyer and Kindt (1981) it is claimed that interaction is regulated by an autonomous level of activity for constituting situations and contexts. Interacting participants may be described in the rough as 'working' on a definition of the situation (eventually together) and some elements of their definition are "labelled" relevant to interpreting the interaction concerned.

The set of these elements constitutes the context. The formation of judgments on literariness can now be represented as follows: contextual constituents relevant to the realization of a text are tested within a situation; the results of this process are used to establish ratings. Contextual constituents are among others:

- author

- institutional conditions of presentation (e.g.: a particular publishing house; performing a play at a theatre)

- other people's opinion on the text

- particular structural properties of the text (e.g. rhythm, metrics)

- treating a particular subject in a text, or the thematic resumption of other literary texts.

As far as, within the text itself or in its larger communicative context, information on contextual constituents is provided, we can speak of "direct context constitution". Standardized forms of direct context constitution are usual informations on author, title, publishing house as well as prefaces, texts on the inside of book-covers etc. Furthermore it must be considered that there are wellestablished conventionalized signals causing preferences for the realization of a text as a literary text (e.g. the designation of the genre "poetry", or of the author's name). If thus the entrance into literary interaction is textually marked by appropriate context constitution, we may speak with some reason of a literary text even in an absolute sense. In general, the realization of a text as a literary text as well as its behavioral consequences are both dependent on the participant, that is, we have to admit that the interpretations assigned to context-constitutive signals by participants are not always compatible or even identical. While participants in face-to-face communication can generally come to an agreement with each other on the interpretation of context signals, the author of a book, however, cannot control the reader's context constitution and he can only hope that the common (in the author's opinion) modes of interpreting and behavior are followed. Thus, in the case of a difference of opinion the author and his reader cannot adjust their interpretations.

of an object as a usuable object, and rating the realized object) should be reconstructed as if the predicate "beautiful" belonged rather to the fir tree than to an object constructed above "fir tree'. 
Among others, the latter point is one of the reasons why I doubt that within the scope of literary interaction all participants always follow one and the same set of conventions disregarding individual, social, situational and textual differences. In particular, I doubt the universality of the polyvalence convention (e.g., I suppose non-professional readers of realistic novels generally do not follow this convention).

Another fundamental argument against Schmidt's thesis of universality is that conventions are seldom (or hardly ever) followed without exception; rather, they are often violated. For instance, participants can easily consent to suspending conventions for certain interactions. Furthermore, it may be the case that participants do not behave according to the conventions although mutually presupposed; and under particular circumstances this violation may even be tacitly accepted or declared unreal for strategic reasons. Moreover, the vagueness of such conventions allows for much latitude in interpreting. In this sense, I would assign, for instance, literariness of Walraff's documentary texts, which explicitly claim to be truthful (i.e., they suggest a violation of the aesthetic convention). In other words, the social sys. tem 'literature' can neither be characterized nor defined via the validity of the two conventions, although without any doubt, these conventions are central elements of literary interaction (partially, participants in jocular everyday communication also behave according to these conventions). Ratings on literariness are in my opinion predominantly influenced by situational and textual (macro-)conditions. On the one hand, this problem can only be solved after a precise specification of these conventions (regarding reception, the polyvalence convention, for instance, in its very unspecifically formulated interpretation by Schmidt, would be valid in all sys. tems of communication, since receivers may always take the liberty of assigning different meanings to a text). On the other hand, we have to wait for the results of empirical investigations, where it must be clarified what exactly the rating of texts as literary texts implies and by which properties literariness is distinct from other text categorizations. Possibly, a sufficient clarification will not be obtained if the meaning of "literary" is investigated by means of direct methods of inquiry or the semantic differential ( $c f$. for investigations of this kind Hintzenberg et al. 1981). In such investigations it is not yet clarified whether the term "literary" together with its intended interpretation belongs to the sociolect of the participant in question. On the other hand, a contrastive semantic analysis must be provided in order to elaborate the specific properties of literary texts in contrast to other types of texts (e.g. jokes).

When I argued above for the hypothesis-view on the two conventions, I referred primarily to the type of formulation, i.e. that generally/frequently certain conventions are valid in literary communication. This type of hypothesis is theoretically to be distinguished from hypotheses like, e.g., generally/frequently certain conventions are supposed to be valid or are explicitly established. This kind of supposing or establishing is an activity in context constitution, but this statement does not purport to characterize the factual behavior of participants. In my opinion, it is neither a feature of literary interaction that generally/frequently participants act 
according to the aesthetic and polyvalence convention, nor that generally/frequently its validity is mutually presupposed. Literary interaction differs at best from communication in other social subsystems insofar as the rate of occurrence of following and supposing conventions - or just the anticipation of following and supposing - is comparatively above average. This might illustrate once more that this possible particularity is inappropriate as a starting point for a general definitional condition of literary interaction; such a condition must provide criteria to decide in any concrete individual case whether or not a communicative action is a literary communicative action.

\section{On the function of logical analyses}

The positive function of logical analyses is illustrated by many hitherto published books and articles of the NIKOL group (cf. Schmidt 1975; Kindt and Schmidt 1976). If the search for truth as well as reliability and intersubjectivity in methodology are regarded as necessary preconditions of the scientific enterprise, a certain degree of explicitly logical control must not be missing [5]. In connection with the necessity of founding the study of literature on a theory of interaction, some logical problems will arise, which do not occur in natural sciences in the same way and which have not been noticed in analytic attempts at reconstructing questions of the traditional study of literature. One of these problems is related to legitimating the usage of vague categories. Apart from treating this problem by means of an example, i.e. the notion of "sonnet", I would like to point out once more the systematic relation between logical analysis and empiricity.

Within the framework of logical analysis two main types of tasks can be distinguished: attempts at the explication of terms on the one hand, and analyzing and testing argumentations on the other. The relevance of the first type - I will confine myself to treating this type only - has been illustrated above by discussing the notions of Kommunikat and literariness.

This discussion, however, did not go into details and was not as concrete as is required for illustrating the degree of exactness necessary for empirical research. As objects for demonstrating my further reflections I would like to use two questions of the traditional study of literature. At the same time, I will make clear that in my opinion it is necessary for the empirical study of literature to be serious about such questions, i.e., we have to scrutinize the possibility of translating such questions into empirical questions. Such a translation, however, is rendered difficult or even impossible by the fact that on the one hand the views of traditional scholars are much too global or inaccurate, and that on the other hand the efforts at positive

[5] In my opinion, it is characteristic - although probably not representative - of the undeveloped relation between traditional scholars of literature and logical control, that one of my students had the following experience when he asked: "How do you know that the text has just this meaning?" and got the answer: "You're making me sick." 
scientific arrangements and at a legitimation of statements have fallen short of the necessary standard.

The authors of the following two statements may surely be supposed to have called on reproducing facts.

(S1) Gryphius' poem “An die Sternen" is a sonnet (cf. Trunz 1965: 19-23)

(S2) Each novel is the story of a degraded looking for authentic values within a world which is itself degraded, but to a much higher extent and in an entirely different way (cf. Goldmann 1972: 18).

Intuitively judged, both statements would be classified as empirically testable hypotheses. A precise analysis, however, would reveal the trivial (but easily overlooked) fact that an empirical testing of a statement can only be provided relative to an interpretation of the statement itself. This interpretation is defined exclusively in relation to an interpretation of the terms used in the statement, so that we now have to ask which interpretation shall be relevant to empirical testing; in other words, it is a question of instances responsible for the choice of interpretations of statements. In (S1), e.g., there are in particular,

(a) the common understanding of assertions of the form " $\mathrm{X}$ is $\mathrm{Y}$ ",

(b) Trunz's assertion that a certain text (i.e. the text he refers to, or the text printed off in his article) is identical to Gryphius' poem,

(c) the interpretation of the notion of sonnet as it is defined in the study of literature.

Apart from an outstanding discussion on the quality of standardized definitions of the "sonnet" in the study of literature, it is obvious that (S1) can be tested without any problems, whereas in case of (S2) it is first of all questionable whether it can be tested empirically, since non-standardized terms are used in (S2). In the following list, three important cases of possible problems of empirical testing are illustrated:

(d) common understanding does not provide a clear interpretation of the linguistic form of the sentence,

(e) a name representing or describing an object in the sentence cannot clearly be related by the reader to the object in concern,

(f) a term used in the sentence cannot clearly be interpreted (e.g. since the term is not a well-defined term in the study of literature, or since the author does not introduce it explicitly).

If intersubjectivity and testability are regarded as indispensable to scientific work, it must be postulated in general that scientific statements can be interpreted clearly in order to exclude cases like (d), (e) and (f) (to be more precise, indirectly defined extensional interpretations are postulated at least). Kindt and Schmidt (1976) 
demonstrate that this postulate remains unsatisfied in hitherto existing studies of literature to an extent much larger than commonly supposed. The deficiency of non-clear interpretability holds even for (S2). In Goldmann, for instance, we look in vain for an explication of his central terms "degraded" and "authentic" value. Even Lukács (1963), to whom Goldmann partially refers, does not provide a clarification of those terms. The elaborated linguistic competence allows for many different interpretations of the terms in question; thus we cannot decide whether (S2) is true or false. Nevertheless, it might be objected that it is quite possible that Goldmann, despite lacking indications, uses those terms in a clear interpretation and that he would have been able to provide for the required explication, if he were asked to. If this is supposed, particularly two conditions must be satisfied. First, it must be possible to assign clearly a global meaning (the "story" of the text) accepted by each competent speaker or hearer; from this the difficulty of representing meanings (cf. Kindt 1976a) arises. Secondly, it must be possible to provide clear and objectifiable judgments on "degradedness and "authenticity" for each meaning, which may be represented again in the object-language; herewith the implicit supposition of a homogeneous system of values is unacceptable. In my opinion, it is no risk claiming that Goldmann did not dispose of means adequate to satisfy the two conditions [6]. In general, the particular problem of testing interpretive as well as evaluating statements in the study of literature is illustrated by this (I shall later discuss this problem at length).

From the discussion on the testability of (S1), an estimation on the quality of definitions in the study of literature is still pending. Can we clearly decide - on the basis of that definition - whether any given text is a sonnet or not a sonnet? In looking over handbooks on the subject, it is striking that suggested definitions of the sonnet are different in meaning and partially inconsistent. That inconsistency is involved by the fact that it is not clearly determined which degree of deviation from the classical form of the sonnet shall be tolerated. Before discussing these problems, I would like to propose a relatively restricted definition of the sonnet by which the above problem of testability is illustrated quite well.

(D) A text $T$ is a sonnet, iff there is a standardized representation in written language of $T$ with the following properties:

(i) $T$ in this form consists of 14 five-foot iambics,

(ii) the 14 lines are subdivided into four stanzas; the first two stanzas consist of four lines each; the last two stanzas consist of three lines each,

(iii) the 14 lines rhyme according to the following pattern: abababbacdeded

Essentially, this definition just makes use of notions which can be allotted to basic notions of the study of literature. Such notions apparently do not require any fur-

[6] Probably, readers of (S2) will rather reconstruct a suitable interpretation according to their knowledge about literature than vice versa test the accuracy of the respective statement by their knowledge according to a generally obligatory in terpretation. 
ther explication. Besides this there are notions from ordinary language and notions immediately understandable in above definition. Consequently, the testing of statements like (S1) should directly be possible. At this point, I would like to dispense with an exact presentation of different single steps in testing-procedures, but I would like to refer to four aspects illustrating problems of testing-procedures, which at first sight are often rated unproblematic. Such problematic aspects are almost always detected if one takes care of a precise logical control over the single steps of the testing-procedure.

Strictly speaking, the required testing presupposes an explicit notion of text relative to the language concerned. In the traditional study of literature, however, no applicable notion of text is introduced. Nevertheless, intuitive decisions on textuality made on the basis of one's own linguistic competence can be legitimated since in most cases they result in homogeneous judgments [7].

In many cases, texts to be investigated are given in the standardized form of written language and are already divided into stanzas and lines. However, we will be confronted with some problems if a text is given as a tape recording. Decisions on underlying rhymes, for instance, may be influenced by transcription. At the same time, there are generally different possibilities of subdividing a text into stanzas and lines. According to the condition in (i), that lines should consist of five foot iambics, one subdivision is clearly favored for testing the conditions of the sonnet: the text must be dividable into 14- or 11 -syllabic lines; the 11 th syllable may be an unaccented syllable. The subdivision becomes quite clear if - as in many definitions of the sonnet - the "endecassillabo" (11 syllables in each line) is postulated. Certainly, there are common definitions which do not contain conditions of meter or quantity of syllables ( $c f$. Kayser 1946: 62); in those cases, the problem of subdividing lines as well as the problem of an admissable quantity of syllables can only be solved, if one requires a clear decision on whether a text is sonnet or not. The traditional study of literature comes to decisions on a certain meter intuitively, by reading the text. It may be supposed that such decisions are homogeneous and objective to a certain extent. Nevertheless, there are many cases where a determination of meter cannot be provided clearly. Consequently, we need more refined analyses of the meter-problem than those provided by common studies of literature [8]. The testing of a certain rhyme-scheme must be based on a definition of rhyme (that is, a definition of the end-rhyme). However, there are many different opinions

[7] In general, there will always be notions in empirical sciences temporarily requiring judgments on the basis of intuition and experience for their interpretations; this is admissible insofar as it is guaranteed that different 'judges' will arrive at much similar judgements according to specifiable criteria. Among the notions requiring explication in applied discourse studies, the notion of text is less problematic than e.g. the notion of meaning; among others, notions which are definable by operations of sign-recognition are unproblematic, e.g. the notion of occurrence, which is used in statements like "The word $W$ occurs in the sentence $S$ ".

[8] E.g., in Gryphius' poem "An die Sternen" the meter of the second line in the third stanza ("Hab ich, indem ich euch betrachtete, gewahrt?") may also be read as an irregular meter: $-U U-U-U U U-$ (that is, the syntagmatic and the metrical accent do not coincide). 
on the necessary degree of purity of rhymes (cf. Kayser 1946: 83-84); thus one has to decide which deviations from the "pure" rhyme shall be admitted (among other things, the question of a standardized pronunciation is important in this context).

Despite those four problematic aspects it may be supposed that in principle (after an agreement on some additional questions of defining and some of secondary importance), one may agree that a given text is / is not a sonnet according to definition (D). In particular, (S1) now proves to be false, since the lines in Gryphius' poem are six-foot iambics; moreover the last two stanzas rhyme according to the scheme ccd ced. Nevertheless, Trunz speaks of this poem as a sonnet; his judgment is apparently based on a less strict definition of the sonnet with regard to conditions (i) and (iii).

If an orthodox-analytical view is advocated, it will be sufficient to claim that Gryphius' poem is a sonnet relative to just one definition of the sonnet. Perhaps a shaking of heads would be evoked by the fact that scholars of literature have hitherto not been able to agree to one homogeneous definition. Such a view, however, does not master underlying problems completely. In general, there is an essential reason for the problems of defining genre notions in the study of literature, that is, authors do not always act according to traditional genre-patterns, but rather deviate from these patterns. Even if textual deviations from a standardized pattern are insignificant, the scholar interested in classification will, however, be quickly inclined to classify the text as an instance of the pattern. Such a procedure can be legitimated under certain conditions. To make this point clear, it is suitable to discuss first the problems of deviation from the view of the participant. An author deviating from a certain genre-pattern generally has knowledge about this pattern, that is, apart from an eventually required objective notion of genre, we will at first have to regard a notion of genre depending on situational elements and the view of the participant, if problems of deviation are to be investigated empirically (e.g., a text is a sonnet for a person in a situation). There are mainly four reasons for an author to deviate from a traditional pattern. Firstly, it may be the case that although knowing the exact conditions of the pattern, he does not want to satisfy these conditions in their essential respects and that he writes a text belonging in his own view to a different, probably new pattern. Secondly, it may be the case that the author sometimes deviates from certain genre-conditions, but nevertheless sticks to the framework of the pattern; that is, e.g., the pattern is insignificantly expanded. Thirdly, the pattern-conditions may possibly be vague in some respect, so that the author eventually makes use only of the latitudes provided by that vagueness. Fourthly, the reason for deviating may be explained by the author's partial knowledge about pattern-conditions and that consequently he acts in production according to his own version of these conditions.

Relative to the concept of the author, the produced text in the cases two to four can be classified as conforming to the pattern, and to be relative to the generally accepted concept in the second case and probably in the third case too. However, it 
is possible that the generally obligatory pattern preceding the actual text production is modified by the author's deviation from this pattern which on principle can happen in all four cases. In general, it must be supposed that each interactional situation allows for certain latitudes in constituting pattern-conditions and for the rating of pattern-conformity. Agreements are regulated by interactional processes of negotiating. For instance, it is now unsuitable to empirical investigation to make use constantly of a definition relative to situations and participants, especially as agreements on the use of genre-notions can be presupposed. Instead of that, it is obvious to introduce a vague and (in case) contextually determined notion. Detailed reasons for logical problems not arising from the use of vague genrenotions [9] cannot be given in this paper: it is fairly easy to see that the classification of a text as a sonnet deviating from the classical form of the sonnet relative to a special historical context (e.g. in the lifetime of the author) is justified if in that context a modified concept is advocated or the text itself is rated near to the standard.

The introduction of vague genre-notions can even be legitimated independent of the goals of an interactionally founded study of literature. In the attempt to develop a system of categories for an almost complete classification of elements within an object domain, it is often suitable to introduce the different systematic categories as mere prototypes. The assignment of a non-prototypical object to one of the categories is legitimated, if the object concerned is nearer to prototypical elements of this category than to those of other categories [10]. The application of that condition, however, presupposes a graduation of scales or neighborhood relations on all relevant characteristical dimensions. It cannot be guaranteed by this that each and every object can be related to a category; but the condition does not allow for inconsistent interrelations in categorizing.

The suggestion to use vague categories in scientific language is inconceivable for the orthodox analytical conception. In fact, the vagueness of notions is solely based on pragmatic reasons for selected modes of representation and does not necessarily have to result in anxieties about logical inconsistency (common approaches based on binary logics, however, must be abandoned). Moreover, it is important to note that there is a difference in principle between the above discussed possibilities of using vague categories with reference to the kind of empirical testing insofar as the second possibility of categorizing is realized according to those properties of the object which are investigated by the scientist, while the first possibility is based on common ratings of participants. I suppose both cases to be relevant to an empirical study of literature. The relevance of categories oriented on situations and participants has been illustrated by the example of the notion of literariness; apart from this, many genre-notions oriented on textual contents must be reconstructed, and

[9] In my opinion, it was Th. Ballmer who first referred to the possibility of using vague categories in linguistics (cf. Ballmer 1977).

[10] In biology, for instance, it is quite common to work with prototypically introduced categories. 
also conventions for literary actions must be reconstructed with orientation on situations and participants [11]. Whereas, e.g., categories more strongly based on formal structures of texts (if this should be required) may also be introduced as independent of participant and situation. This holds for e.g. the notion of sonnet, if one is ready to dispense with partially common definitional conditions concerning meaning and/or aesthetics [12]. However, it seems to be inappropriate to construct a notion of sonnet as vague as subsuming all factually given varieties; that is, some deviations are reaching much too far. In my opinion, it would be convenient to introduce additionally the basic notion of 'sonnet-like text' as well as to specify (as usual) the different standardized forms.

To what inconsistencies in argumentation an insufficient logical clarification of genre-notions may lead, shall be exemplified finally by Wapnewski's investigation in 1957. Wapnewski is mainly concerned with proving Walther von der Vogelweide's poem "Nemt, frowe, disen kranz" to be a pastoral poem. In this investigation, arguments on the lacking of the 'ouverture habituelle' common to pastorals are most important. Indeed, Wapnewski himself hesitates whether to rate the ouverture habituelle as a primary or a secondary feature of pastorals. His description is rather contradictory in that respect: on pp. 138-139 and 147 respectively, both views are advocated. Wapnewski's argunentation is contradictory in a similar way: on the one hand, it is a blemish to him that Walther's poem does not include an ouverture habituelle; on the other hand, he continues rating that poems as a pastoral ("ich vermag mich auch nicht zu entschliessen, Walthers Pastourelle dieses Makels halber keine Pastourelle sein zu lassen" (1957: 147)). If the ouverture habituelle is a secondary feature of pastorals, then it is no blemish for a pastoral not to show this feature. If however it is a primary feature, Walther's poem is not a pastoral in the strict sense. It would be legitimate to rate that poem as a pastoral, if participant-ratings (of the author, of receivers of that time etc.) were proved, or if the lacking of the ouverture habituelle were admitted for an objective notion of pastoral in accordance with a determination of a vagueness-area.

\section{Linguistic and methods of interpretation}

As I have mentioned in the introductory section, I am convinced that the interpretation [13] of texts is still a central task for the study of literature. If effects of literary texts are to be investigated in order to discover, e.g, changes or stabilizations of opinions on the part of the receiver, we will have to provide statements on

[11] This holds likewise for categories used in linguistics. In Kindt 1980a, I deal with the explication of the notion of argumentation as an example.

[12] Cf. e.g. Wilpert 1969: 575, where he claims "die Quartette dienen der Exposition in der Aufzählung von Gleichartigem oder der Darstellung der Gegensätze, die in den Terzetten zu reinem Ebenmass vereinigt, konzentriert und zum mäch tigen Schlussakkord geführt werden".

[13] 'Interpretation' and 'meaning' are now used as in semantics. 
textual meaning and evaluation as decisively influential variables. Such statements, however, cannot be obtained directly by referring to one's own subjective experience of reception; on principle, rather those meanings/evaluations must be investigated which are assigned to texts by receivers of the analyzed social group. Unfortunately, according to the present state of research, an empirical inquiry of meanings/evaluations can neither be executed by directive interviewing alone, since processes of constituting meanings and evaluations are highly unconscious, nor in the absence of empirically corroborated theories of meaning and evaluation. Thus, as in the past, we cannot do without interpretive methods, but we should attend to a strict methodical control.

As before, I would now like to point out problems of meaning and evaluation in statements of the study of literature by discussing procedures and questions of the traditional study of literature. For instance, the definition of the sonnet given by Wilpert in 1961 (cf. ch. 2) consists of elements with regard to meaning and evaluation, and thus empirical testing is rendered difficult. The criteria postulated are neither as clear in themselves as to allow intuitive decisions on their validity unequivocally nor can different persons be supposed to be providing a sufficiently homogeneous interpretation of these criteria.

It is a problem that statements in studies of literature depend on norms of interpretation and value judgments specific to individuals and groups. On the one hand, much more questions are raised by this problem than commonly supposed, since nearly each question of the traditional study of literature is related to textual mean. ing and evaluation. This holds even for the question in the preceding chapter whether Walter von der Vogelweide's poem "Nemt, frowe, disen Kranz" is a pastoral, i.e. the definition of the pastoral is mainly based on conditions with regard to content (cf. Wapnewski 1957: 146-47). On the other hand, above problem directly concerns all questions implying explicit judgments on meaning or aesthetic, political etc. values of texts. A characteristic example of this problem is the following statement:

(S3) Goethe's poem "Grenzen der Menschheit" symbolizes impressively a power as against which solely a childlike, timid and worshipping attitude of the ego and with that of human nature itself is suitable (cf. Conrady 1974: 161).

Statements such as these are common to hitherto studies of literature and sometimes even reach the border of absurdity; evidently, they cannot be tested empirically (in a strict sense), since their validity can neither be judged intuitively and reliably, nor are there any proper intersubjective testing-procedures. From the point of view of the empirical study of literature, interpretive and evaluative activities in the traditional study of literature, are results of a misdirected development supported by hermeneutical dogmas and based on unreflective and partially inconsistent views on human communication. If proponents of the traditional study of literature had been conscious of the fact that interpretation and evaluation are in a 
high degree specific to social groups [14] and that, at the same time, both may become more and more optional with an increasing degree of detailedness, they would not have been induced to interpret texts thus naive, and noncritical against their subjective results of reception. Naturally there is no problem in claiming, e.g. that it is stated in Goethe's poem "Grenzen der Menschheit": Man shall not overestimate himself, he shall not be presumptious, not be hybrid (cf. Conrady 1974: 173). This statement may be interpreted approximately as an empirically testable statement, if the diction " $Y$ is stated in text $T$ " is rendered precisely as follows ( $c f$. also Kindt 1976a), e.g. :

Each competent speaker as a receiver of a text $T$ assigns meaning to $T$, particularly implying $Y$.

This diction is admissible as an abbreviation insofar as the postulated content of the statement may be presupposed as commonly obligatory. A noncritical use of such dictions, however, will result in well-known dilemmas of hermeneutic ideology and a blockage of empirical analysis. Moreover, problems of interpretation in the study of literature - in contrast to other discourse studies - are intensified insofar as in literary communication, interpretive notions are much more dependent upon groups and situation, and as there is much more latitude in the interpretation. This explains why the lacking consciousness for the methodology of interpretation could have had such disadvantageous consequences for the study of literature. It is altogether not being denied here that there is a certain empirical starting-point [15] for traditional investigations concerned with textual meaning and evaluation. That starting-point is based on the daily experience that textual meaning and evaluation can be discussed significantly and that in many cases they may be even be judged homogeneously.

The incompetence of the traditional study of literature to master the problems of interpretation must not be discussed irrespective of the question which problemsolving offers were actually provided by linguistics. Roughly speaking, scholars of literature could obtain nearly no usable methods of interpretation from linguistics. On the one hand, a sufficiently reflective theoretical discussion in semantics has just begun, i.e. in the era of logical grammar [16]. Up to now, mainly static approaches like e.g. structuralism have been propounded (thus, the Saussurian notion of sign induces to the introduction of an autonomous concept of meaning). On the other hand, semantics cannot be regarded thus far as an empirical discipline (there are at most tendencies towards a systematic empirization). In particular, there are as yet

[14] Although subjectivity has been stressed verbally by scholars of literature, they have not drawn necessary behavioral conclusions concerning tolerance and concerning careful diction.

[15] This is concealed, for instance, by the postulated (cf. Mecklenburg and Müller 1974) or accepted (cf. Conrady 1974) distinction between empirical, interpretive and normative sentences.

[16] This recent discussion has hardly been noticed by scholars of literature. 
no empirically corroborated methods of interpretation. Certainly, the discussion between linguists and scholars of literature has furnished many interesting results for the analysis of literary texts, e.g. by the use of structuralist methods. These methods, however, are not appropriate or sufficient for a controlled, empirically testable textual interpretation ( $c f$. e.g. Kindt 1976b). Frequently, many scholars were in a euphoric mood of starting afresh - for the last time, in connection with the outset of textlinguistics - insofar as they hoped for most promising possibilities by a cooperation of linguists and scholars of literature. The subsequently great disappointment about unfulfilled expectations concerning the application of linguistic methods for textual interpretation brought about unfortunately and unjustly the present lack of the philologist's interest in linguistics.

There are of course plausible explanations for the inadequacies of linguistic semantics. Thus, the immense complexity of meaning-constitutive processes may explain why semantics has not yet been developed beyond such special problems as problems of ambiguity or presupposition. Particularly, it looks as though the development of effectively applicable methods of linguistic interpretation may be rendered impossible by the open endedness of the interpretability of linguistic expressions in respect of the contextually regulated processes of modifying and specifying meaning: such methods would apparently have to generate the complete set of meanings of a text for each possible context, and to formulate preferences, if different meanings are for choice. Moreover, the application of those methods would presuppose that one knew prior to interpretation which contextual informations are altogether necessary (how much do we have to know about the 'Thirty Years War' for adequately interpreting Grimmelshausen's novel "Der abenteuerliche Simplicissimus"?).

However complex meaning-constitutive processes may be, we must not overlook the fact that obviously communicative participants mostly or at least frequently come to an understanding with each other. Although one word may hypothetically take an infinity of meanings ( $c f$. Kindt 1981), it does generally not raise any difficulties in communication to select one meaning or just the appropriate one. In my opinion, the only plausible explanation for this is that on the one hand, communicative participants are frequently applying highly conventionalized procedures of meaning-construction and that on the other hand, the application of all procedures including non-conventionalized procedures of meaning-constitution as well is interactionally regulated and controlled by conventionalized procedures of negotiation. Those latter procedures, which also take part in context-constitution (cf. section 1) have first met with the linguist's range of vision in the frameworks of textlinguistics and conversational analysis. The development of linguistic methods of interpretation presupposes in my opinion that, in advance, interactionally common procedures of meaning-construction as well as procedures regulating the application of those procedures of meaning-construction have been investigated systematically. As communicative participants are generally unaware of these procedures and their factual application, linguists will be unable to investigate them, either by introspec- 
tion or by methods of interviewing. A successful access to these procedures can only be realized by interpretive methods and/or communicative experiments. But I do not take it for granted that results of such investigations available in the short run would be sufficient to provide an empirically corroborated and complete device for textual interpretation. This restricted expectation, however, does not imply that results once achieved could not be used for an empirically adequate textual interpretation. It is only of consequence here that even in the long run, we will not dispose of any mechanically applicable device for textual interpretation, but that, in many cases, we will still have to rely on interpretive methods.

Whether specific procedures of meaning-construction and its regulation might be applied in literary interaction is a question arousing particular interest. This question concerns classical fields between linguistics and the study of literature; but I think that new attempts from a new perspective are necessary for an answer to this question. Assumptions such as, metaphorization is a typical feature of literary interaction, must be tested empirically and their possible significance must be formulated in a reflective manner. There is probably only a gradual difference in the application of typically literary procedures of meaning-construction; furthermore, we have to distinguish the fact that the application of such procedures is directed by the structure of the text from the fact that such procedures are factually applied by certain readers. Besides characteristic features related to procedures of meaningconstruction, literary interaction may also show particularities of regulating communication. For instance, the polyvalence convention (cf. Schmidt 1980) must be confirmed empirically on this level, that is, by the fact that participants in literary interaction partially dispense with a strict regulation of mutual understanding, and that partially a particularly extensive application of certain procedures of meaningconstruction is required. But we may also conceive quite different procedures of regulating communication. This regulation might be directed especially to certain specifically thematic aspects of meaning-constitution (perhaps in reading novels, assemblages of problems and conflicts may be worked out very intensively, whereas the reading of poems might rather evoke assemblages of feelings). At this point, I would not like to continue speculating about characteristic features of literary interaction, but would rather put forward my assumption that the domain of literary interaction cannot be characterized sufficiently by two or three behavioral regularities. I think the situation to be much more complicated and that very many thorough investigations must be executed for defining relevant features of literary interaction.

A particular problem of interpreting in the study of literature is based on the fact that literary texts as they are to be interpreted according to traditional goals do not represent a communicative process interactively performed by the author and his reader, but only contain the linguistic 'output' of the author. Consequently, the central presupposition for an interpretive approach oriented on interaction is not satisfied, i.e., the presupposition that the constitutive mechanism to be investigated could be inferred from interactively performed processes of negotiation. First of all, 
I mean that an isolated interpretation of literary texts is hardly fit for investigating typically literary procedures of meaning construction and procedures of negotiation. For producing interpretations, however, we can only make a limited use of the given knowledge of such procedures, i.e., that knowledge may at most be used for the construction of hypotheses on author-intentions, or for a hypothesized 'average' interpretation, but not for constructing interpretations of specific groups of receivers. Consequently, we may discern for instance, an intended local suspension of a semantic rule or a context-constitutive activity. As a further consequence of the difficulty mentioned above, the investigation of literary interaction necessitates an analysis of larger interactional contexts. In this way, we could observe processes of negotiation, which are however temporarily postponed. The principles of meaning-constitution in literary interaction must be partially inferable from the communication on texts following the reading-process. In general, I think the analysis of communicative processes in the field of producing and receiving literary texts will provide important possibilities for getting information about the conditions and functions of literary interaction.

My plea for using interpretive methods needs a demarcating remark, especially in a paper addressed to scholars of literature. But not all activities being assigned to the category "interpretive" within the frameworks of linguistic and sociology are in my opinion scientifically solid. After all, an acceptable methodology of interpretive methods has to be developed (in Kindt 1980a, I formulated some preliminary methodological rules). If, on the one hand, it is considered that material analyses are executed by many authors in an unsystematical and logically uncontrolled way, and that, on the other hand, one is again confronted with vigorously expressed, but well-known immunizing strategies of hermeneutics (cf. e.g Oevermann et al. 1979), then it is hardly foreseeable whether the propounding of interpretive methods may be responsible for a swing of the pendulum back to hermeneutic 'chaos'. This, however, would have disagreeable consequences for me.

\section{On normative tasks}

A standard theme in handbooks of the general study of literature is "the function of literature'. In corresponding sections, it is often apodictically claimed what function literature fulfills or should fulfill. Such statements are rather useless unless it is investigated whether literature really fulfills the function postulated or whether there are any chances at all of realizing this function in society. In discussions on this subject, there are neither dispositions to deal with the theme empirically, nor are those discussions sufficiently theoretically differentiated. For instance, it is not considered sufficiently that the question of function must be related to different social constellations and to different groups of participants. In executing investigations on the factual social function of literature, the empirical theory of literature is confronted with a vast and interesting field of tasks. Naturally, such empirical research 
could demonstrate that negative judgments must be attributed to certain literary interactions as these are opposed to explicitly/implicitly postulated functions of literature or to other social values. In my opinion, it would be unreasonable for a scholar of literature after having investigated such negative phenomena to restrict himself to publishing his research work without any critical evaluation of those phenomena and without discussing the question of how they might be avoided. In serious cases, the scientist in his role as a scientist on the political level ought to feel obligated to advocate actively the cessation of the abuse in concern [17]. It is, however, somewhat problematic to postulate critical evaluation and eventually political activity, as their unrestricted realization might result for instance in unlegitimated tutelage or proscription of individuals. Thus it is necessary to formulate conditions allowing scientists to be acting normatively. Before I shall turn to discuss the formulation of such conditions, I would like to give a first estimation on normative goals of the traditional study of literature.

Generally, statements of scholars of literature on the tasks of the study of literature must be regarded in connection with the corresponding historically and socially affected views on desired functions of literature and science. By corresponding views on the function of literature, tasks are defined concerning the foundation, mediation, observance and support of norms specific to functions. Whereas postulates concerning the function of science rather operate upon the mode in which these tasks are put into practice. Looking over common goals of the study of literature, we ascertain a plain discrepancy between these goals and the factual activities of the scholars of literature. On the one hand, many postulated goals such as, e.g. emancipation, education, humanity etc., are much too general and are not precisely defined. On the other hand, the relevance of interpreting and other activities concerned with the realization of such goals is not explicitly reflected upon; and it would be necessary to make the intermediate 'steps' of functional connections more precise. With regard to this Conrady's attempt in 1974 at establishing a connection between the "realization of humanity" and a critical treatment of literature is almost an exception. Afterall, it seems quite dubious to me that the above-mentioned goals may be attained by methods hitherto practiced in the study of literature. The subjectivity of philological interpretations (although pretending scientific authority), the uncritical use of language, and the blockage of argumentative precision might partially contradict the postulated goals; notwithstanding attentiveness to certain social problems, such practice results in an incapacity for systematic analysis of problems, a lack of discrimination, or feelings of weakness in the presence of authorities, or in the construction of a self-supporting intellectual

[17] It is common to practice that after the publication of their research work, scientists frequently do not feel responsible for whether and how their results are utilized in society, although on account of a necessary positive self-estimation they certainly do not always believe their findings to be without aftermaths. In my opinion, scientists themselves should take account of an appropriate utilization of their results, and consequently, they should participate in developing appropriate democratic controlling devices. 
world far from reality. Although this thesis is not proved by empirical research, it is nevertheless supported by many reports of personal experience.

For the purpose of illustrating normative tasks of the traditional study of literature more concretely, I would like to discuss two examples from Conrady (1974). The first example is related to the fact that Conrady - with reference to the goal of "humanizing human life and society" - criticizes many Germanic scholars for having accepted the value-system of National Socialism in the time before and after 1933 (cf. Conrady 1974: 43, 66). His criticism is based on a (partially implicit) argumentation, which can be subdivided approximately into four steps as follows:

- Conrady observes that some scholars produced evaluations in their works according to certain "nationalistic" principles.

- Conrady suggests that those principles contradict the principles of humanity (in the sense of his deformation), as they deny e.g. the equality of people.

- Conrady presupposes that scholars of literature publicly advocating inhuman principles are (or were) obstructing the realization of humanity.

- In Conrady's point of view - with reference to a certain system of values - the realization of humanity is worth striving for; and consequently, obstructions to humanization are reprobated.

In my opinion, a procedure oriented towards those four steps could also be realized in the empirical study of literature, and under certain conditions, this could also be legitimated ethic-scientifically. The first step of argumentation consists of a statement about the behavior of certain people. Irrespective of the fact that in particular cases, it may be difficult to decide whether a certain human behavior is present or not, yet in order to do justice to the people concerned, it is necessary to make only such statements that can be supported by unobjectionably applicable and empirically interpreted criteria. The second step refers to the result of a comparison between different statements on values. A comparison like that can be provided by purely logical operations, that is, with recourse to the definition of the notions occurring in the statements. The third step is essentially based on the general hypothesis that there is a correlation between the scientist's publicly advocating certain principles and their realization in society, which is a purely empirical hypothesis. Finally, even the fourth step of Conrady's argumentation is commensurable with empirical science in principle, as relative to an explicit, axiomatically presupposed system of values (which however need not be accepted by each member of a society) it can be decided by logical deduction which states of affairs in human society are favorable according to the system of values and which actions can be rated positively or negatively with respect to the required establishment of positive states of affairs. But it is exactly this step, Conrady did not reflect on sufficiently (and he even says that he will content himself with allusions on this subject). On the one hand, Conrady does not completely explicate the system of values underlying his argumentation; on the other hand, it is not very clear how Conrady par- 
ticularizes the foundational interrelations between norms and values (it appears to me as if Conrady has an eye upon aspects of empirical foundation, as he rates such values as positive which might help mankind lead a happy ("glückerfüllt") life; $c f$. 1974: 79).

As a second example, I will again refer to Conrady's discussion about Goethe's poem "Grenzen der Menschheit" (cf. 1974: 154-174). There are three steps in his discussion: at first, Conrady gives an interpretation of Goethe's poem ( $c f$. statement (S3) in the third section of the present article). Later on, he gives an outline of Goethe's Weimar period and of the experience Goethe underwent then. These are the data Conrady refers to in interpreting that poem. Accordingly, the attempts to explain the interpretively postulated intention of the poem to be a glorification and compensation of certain disappointments of Goethe; and Conrady also criticizes that statement, as among other things, it would conceal real conflicts ("reale Widersprüche") and thus it would involve the danger of assisting in stabilizing a submissive attitude ("Stabilisierung einer Unterwerfungshaltung") ( $c f$. Conrady 1974: 172).

Is Conrady as a scholar of literature authorized in principle to criticize Goethe in this way? And in detail what conditions must be satisfied by such a critical discussion, if it claims to be scientific? From a global point of view, we have to admit that Conrady is allowed to criticize Goethe, as criticism can be founded within the frameworks of a normative definition of the social function and responsibility of authors. Here we have to assume the existence of enlightening duties and a responsibility of authors towards changing society in regard to its humanization. However, Conrady's explication of his different argumentative steps could be objected to:

- The presupposed determination of function is not explicated; thus, the problem of its legitimation cannot be dealt with (and at this point, it would have been necessary to legitimate why the attribution of certain social tasks to authors should also be adequate in the case of Goethe).

- The attempt at explaining the intention of the poem to be a glorification and a compensation of disappointments remains incomplete.

- The interpretation of the poem is hardly secured in its important respects, and it is precipitately declared to be Goethe's intention (it should have to be called into question, e.g. whether Goethe really provides a general statement in his poem, or what is meant by speaking of gods, or whether the poem contains a general tendency towards accepting contradictory social conditions).

The discussion of those two examples might have illustrated some conditions which must be satisfied, if normative activities in science are to be legitimate actions. In the following section, I would like to emphasize two postulates: the explication of underlying systems of norms and values; particular accuracy in argumentation and in the use of empirical statements.

(a) The first postulate means that normative statements and value judgments must not be made without reference to explicitly expressed systems of notms and 
values. In principle, there are no restrictions to an axiomatic foundation of such systems; but the statements derived from them could only be obligatory to a person accepting these systems (and this is why the postulate of explicitness is so important: the claim of normative statements and value judgments to be obligatory can be judged adequately only by someone who knows their premises). Nevertheless it is admissible to ask about the legitimation of the presupposed system of norms and values. If the presupposed system can logically be reduced to generally accepted basic norms or values, then the degrec of obligation related to derived normative and evaluative statements is correspondingly high. But scientists answering the question of legitimation must also be allowed to advocate exclusively their very own norms and values. Moreover, I think that the scope of norms and values which can partially be legitimated empirically, extends much further than commonly supposed; and in principle, there is also no border for questions on the empirical legitimation of norms and values. However, the empirical interrelations between certain norms/values and their underlying individual and social interests cannot be discerned right off, and generally they are hardly investigated scientifically.

(b) It goes without saying that scientists are liable to utmost argumentative accuracy, if it is taken into consideration that incorrect normative activities in science might have negative consequences on social life. My second postulate involves for instance, that only empirically sufficiently tested statements on facts are admissible, that the theories used are empirically corroborated, and that argumentation can be controlled logically and be represented explicitly (in particular to test the correctness of deducing normative statements and value judgments). Sometimes, however, there are situations in which a scientist subjectively assigns negative values to certain actions, to those of his colleagues, for instance, and in which he thinks himself to be obligated of criticizing and preventing those actions, although for the present he cannot yet prove the opined negative consequences. Does the scientist in a situation like that have to dispense with public criticism and the possibility of preventing the consequences he is worrying about? In my opinion, this question can clearly be answered in the negative: actions engaged in politics and methodically based knowledge need not be incommensurably opposite domains in science. In the case discussed above, it is sufficient that all problematic parts of the argumentation concerning the required criticism, i.e., parts concealing argumentative deficiencies by means of assumptions are unequivocally marked as such. In other words, the argumentation must clearly exhibit the preconditions of the criticism and the status of its preconditions (e.g. concerning their degree of reliability). By satisfying that condition, it is not necessary to give up criticism completely (criticism is at best restricted in its efficiency). But in this way, criticism becomes scientifically controllable and can be appraised more precisely concerning its legitimation, by which - in principle at least - it may be easier to prevent manipulations occurring in the name of science.

In like manner and quite recently some stock-takings concerning the standards of argumentation in the traditional study of literature have been carried out, 
it should also be investigated more precisely whether and in how far traditional normative tasks are acceptable in their principles and realizations for the empirical study of literature. Probably, an investigation like that would reveal that the various types of normative activities in the traditional study of literature must be judged quite differently. Certainly, the insufficiently executed argumentation as well as the missing of empirical foundation will be criticized. But as the above two examples demonstrate, we can at least accept the general frame of some such activities. It would certainly go beyond the scope of the present paper, if traditional studies were thoroughly discussed under this aspect; but at least I would like to refer to some problematic points. Reproaches such as e.g. Conrady heaped upon Goethe, or the reproach for glorifying violence (a criminal fact), if merely based on the interpretation of a text, are problematic insofar as the consequences of reading a certain text cannot be predicted offhand for different readers. The importance of an empirically founded answer to that problem is illustrated for instance by repeated (and not yet decided) discussions on whether the presentation of violence on television stimulates acts of violence or whether this offers a possibility for compensating aggressions. Here it once more becomes clear that a detailed empirical analysis of the factual functions of literature must precede normative activities. Such analysis, however, cannot be executed by an armchair scholar of literature, and it must be differentiated according to groups of readers. And only by the results of such analyses it can be adequately rated what 'damage' an author will do producing a text of a certain type. In general, the traditional study of literature may be reproached for its deficiency of an insufficient functional analysis. After all, traditional studies lack a clear distinction between scientific and feuilletonistic literary criticism. Such a distinction is absolutely necessary, since respective criticisms are based on institutionally differently defined goals, different claims on results, and different assumptions about the preconditions of addressees and their expectancies. For instance, a statement of the type "the author glorifies violence in his text" evokes different obligations and rights according to circumstances: if it occurs in a review, the reader can only very indirectly rely on the truth of that statement and, in principle, he has to test it critically before accepting; whereas in the case of a report presenting the statement as a scientific result, the reader is allowed to suppose the truth of the statement, despite a general obligation to criticism.

Besides the very abstract goals enumerated at the beginning of this paper, which are concerned with normative and pedagogical aspects, there are others and partly more concrete goals of the traditional study of literature; some key-words are e.g.: "contributing to the growth of awareness"; "educating competent readers"; "orientation towards action"; "criticism and acquisition of values of social and individual morals". Although such goals must be taken seriously within the context of literary instruction, their adoption by the study of literature is however based on a funda. mental misunderstanding and over-rating of the possibilities of that science. This view shall be illustrated in the following paragraph.

If, as a starting-point of a scientific investigation critical of society, it is asked 
how a picture of social life textually presented by an author shall be rated, then this question must be answered on the basis of a textual interpretation adequate to the author's intention. The determination of such an interpretation is clearly an empirical task. But however, it is a well-known difficulty to provide empirically reliable statements on adequate textual interpretations. In order to evade that difficulty, we may regard the desired statements on textual interpretation as logical premises to the entire argumentation, and instead of the first question, we may ask as follows: "If the picture of social life presented by the author has these properties, how is it then to be rated?". Most probably, this modification will have no negative effect, if for example, the investigation is restricted to a comparison between the conditions of social life and those of the supposed picture, and e.g. to a positive evaluation of the latter. That modification, however, would have a decisive influence on the explanatory power of the investigation, if in addition, evidences for the author's progressivistic attitude were required. In the context of a critical investigation of society, we can thus raise different claims on textual interpretations. On the one hand, there are tasks providing empirical statements on potential or factual interpretations from authors or receivers. On the other hand, there are tasks where interpretations only serve as a starting-point or an illustration for the scientific discussion of social problems. For investigations of that kind, it is necessary to determine the argumentative status of interpretations and their empirical claim. Investigations in which analyses of literature are only illustrative examples are, however, placed outside of a domain of activity that should be called the study of literature. In principle, such investigations can be reduced of their statements on literature, and thus belong to sociology rather than to the study of literature. Or by means of these statements and with reference to the text and its author, it is attempted to legitimate certain normative statements or value judgments, that is, to legitimate for instance, the wish for a certain utopian society; but in the frameworks of science, this would have to be rated as a manipulation.

But how do wo have to rate investigations which in contrast to the case just mentioned are substantially oriented towards interpretation, that is, an empirical investigation of the textually presented critical position of an author. Do such investigations actually give occasion or even the obligation for a scholar of literature to interfere with the processes of mediating "values of the social and individual morals"? Scholars of literature indeed postulate suchlike obligations. Such obligations - as exemplified by common views (cf., e.g., Conrady 1974: 64) - are not related primarily to the accomplishment of the individual personality as Humboldt stated, but to the social accomplishment of society on the whole. More generally scholars of literature believe that they are obligated to play the role of mediators between literature and literary text receivers. The realization of this mediative function is often referred to as a reason why the use of professional terminology, as it is unintelligible to amateurs, should be avoided in the study of literature, and also why theoretical discussions should not supersede the practical dealing with literature (cf. Conrady 1974: 11,12). In my opinion, the self-assignment of the mediat- 
ing role and the postulate of intelligibility are based on two misunderstandings. Firstly, according to the cooperation between scientific and educational institutions, it is not a genuine task for the study of literature to mediate itself social norms and values, but at best to elaborate certain scientific foundations for that task (e.g., by developing methods of analysis) [18]. For this reason, objections to the use of professional terminologies are inappropriate. The use of such terminology is rather a necessary precondition for the emancipatory claims of the study of literature, in as far as it is a guarantee for unequivocal interpretations of statements, and by this, statements of the study of literature become scientifically discussible [19].

Secondly, research and the mediation of research are distinct in each science; they are both important enterprises, but they should not be confounded with one another [20].

In particular, it would be absurd if the legitimate needs for mediation were obstacles to research (just imagine that it would be demanded of physics to dispense with the use of mathematical theories and formulae on account of a postulate of intelligibleness). Although it is legitimate to demand that science should be oriented towards social needs, the me thods of acquiring knowledge, however, must be effective and true-to-fact, but they cannot be oriented towards the needs for information (which are by the way very different) in any other social domain outside of science. Furthermore, it cannot be expected that within the frameworks of mediating processes the complexity of the respective research processes could be represented completely; however, we do not have to require completeness, if we can trust in the reliability of scientific results. On the whole, we can observe that in rating the problems of mediation, traditional scholars of literature fluctuate between different views: on the one hand, they assert a claim of scientific character to their work, and on the other hand they again withdraw their claim with reference to their general social task of mediation, or with reference to the fact that at any rate, they could not reach an irrevocability of their results on account of their individual anticipation, and thus they would rather have the function of providing suggestions ( $c f$. e.g. Pollmann 1973: 60). The problems of demarcation indicated in this paper have always played a major role in discussions between scholars of literature, but never were they solved unequivocally and definitively.

[18] Besides disciplinary education, universities have educational functions on the level of political socialization, i.e., in regard to practicing democratic rules in the frame of participating in self-administration.

[19] However, it must be supposed that scholars of literature, who in tend to restrict the introduction of professional terminologies with reference to their mediative tasks, of ten overrate the intelligibility of their own publications as well as their factual circle of readers, and consequently, they likewise overrate the possibilities of the study of literature of having direct influence on society. The regard for mediative tasks which is executed in the wrong place decisively obstructs a stronger theoretical foundation of the study of literature.

[20] This does not mean that scientists would not have the task to cooperate in mediating processes and to write e.g. popular scientific articles. 
On the basis of these considerations, I would summarize that the empirical study of literature should only accept a small part of the normative goals postulated in the traditional study of literature. As far as the field of mediating social norms and values is concerned, at best an (indirect) mediation of norms and values of the litera. ture-system is within the field of duties, supposing that such values could be derived from generally accepted systems of norms and values, and that they could be founded empirically. In other words, before making normative statements about the functions of literature within a certain phase of a society, the appropriateness of such functional determinations must be tested empirically. Even faced with the nightmare of literary interaction under state control, or the idea of a return to old rites of reading and interpreting at school, I still believe that standardizations offering tolerance and protecting individual interests are appropriate in the domain of literary interaction. Besides statements about the appropriateness of norms and values, normative activities are admissible whenever interactions and their consequences are judged on the basis of hypothetically supposed or previously founded norms and values.

\section{References}

Ballmer, Th. 1977. The instrumental character of natural language. University of Bochum.

Conrady, K.O. 1974. Literature und Germanisk als Herausforderung. Frankfurt: Suhrkamp. Goldmann, L. 1972. Sociologie des Romans. Darmstadt: Luchterhand.

Hintzenberg, D., S.J. Schmidt and R. Zobel. 1981. Zur Literaturbegriff in der Bundesrepublik Deutschland. Braunschweig: Vieweg.

Kallmeyer, W. and W. Kindt. 1979. 'Die empirische Untersuchung von Verstehensproblemen'. In: Zwischenstation Universität Bielefeld 1979. Bielefeld: Universität Bielefeld.

Kallmeyer, W. and W. Kindt. 1981. Kontext - Konstitution. Ms (in prep.)

Kayser, W. 1946. Kleine deutsche Versschule. Bern: Francke.

Kayser, W. 1960. Das sprachliche Kunstwerk. Bern: Francke.

Kindt, W. 1976a. Überlegungen zu Oskar Seidlins "Stiluntersuchungen an einem Thomas-MannSatz". In: W. Kindt and S.J. Schmidt, eds. pp. 56-92.

Kindt, W. 1976b. Analyse des Aufsatzes "'Les Chats' de Charles Baudelaire" von Roman Jakobson und Claude Lévi-Strauss'. In: W. Kindt and S.J. Schmidt, eds. pp. 105-115.

Kindt, W. 1980a. 'Methodologische Probleme empirischer Argumentationsforschung'. In: W. Kühlwein A. Raasch, eds., Sprache und Verstehen. Tübingen: Narr.

Kindt, W. 1980b. 'Komplexität und Verständlichkeit von Texten'. In: D. Hintzenberg, 1981. pp. 217-238.

Kindt, W. 1981. 'Word Semantics and conversational analysis'. In: H.J. Eikmeyer and H. Rieser, Words, worlds and contexts. Berlin: de Gruyter.

Kindt, W. and S.J. Schmidt, eds. 1976. Interpretationsanalysen. München: Fink.

Kindt, W. and S.J. Schmidt. 1979. 'Motivationen und Aspekte einer empirischen Literaturwissenschaft'. In: S.J. Schmidt, ed., Empirie in Literatur- und Kunstwissenschaft. München: Fink.

Lukács, G. 1963. Die Theorie des Romans. Neuwied: Luchterhand.

Mecklenburg, N. and H. Müller. 1974. Erkenntnisinteresse und Literaturwissenschaft. Stuttgart: Kohlhammer.

Oevermann et al. 1979. "Die Methodologie einer "objektiven" Hermeneutik und ihre allgemeine 
forschungslogische Bedeutung in den Sozialwissenschaften'. In: H.-G. Soeffner, ed., Interpretative Verfahren in den Sozial- und Textwissenschaften. Stuttgart: Metzler

Pollmann, L. 1973. Literaturwissenschaft und Methode. Frankfurt: Athenäum.

Schmidt, S.J. 1975. Literaturwissenschaft als argumentierende Wissenschaft. München: Fink.

Schmidt, S.J. 1980. Grundriss der empirischen Literaturwissenschaft, Vol. 1. Braunschweig: Vieweg.

Trunz, E. 1965. 'Andreas Gryphius Gedicht "an die Sternen"'. In: J. Schillemeit, ed., Deutsche Lyrik von Weckherlin bis Benn. Frankfurt: Fischer.

Wapnewski, P. 1957. Walthers Lied von der Traumliebe $(74,20)$ und die deutschsprachige Pastourelle. Euphorion 51: 113-150.

Wellek, R. and A. Warren. 1978. Theory of literature. Harmondsworth: Penguin.

v. Wilpert, G. 1969. Sachwörterbuch der Literatur. Stuttgart: Kröner.

Walther Kindt, lecturer for linguistics at the University of Bielefeld; dissertation in mathematics and logics (1973); main interests and publications on semantics; among his publications on the study of literature is "Interpretationsanalysen" (1976). Since 1980 he has been executing a project on "Communication on art". 